\title{
Compliance with Handwashing at Two Intensive Care Units in São Paulo
}

\author{
Guilherme H.C. Furtado, ${ }^{1,2}$, \\ Solange L. Santana ${ }^{1}$, Ana Paula Coutinho ${ }^{1}$, \\ Luciana B. Perdiz ${ }^{2}$, Sérgio B. Wey ${ }^{1}$ \\ and Eduardo A.S. Medeiros ${ }^{1}$
}

\author{
${ }^{1}$ Healthcare Epidemiology Committee, Division of Infectious \\ Diseases, Federal University of São Paulo, São Paulo, SP; \\ ${ }^{2}$ Infection Control Committee, Diadema State Hospital, Federal \\ University of São Paulo; Diadema, SP, Brazil
}

\begin{abstract}
Handwashing compliance was compared at two medical- surgical intensive care units (ICUs) of a teaching and a non-teaching hospital. The mean compliance was $22.2 \%$ and $\mathbf{4 2 . 6 \%}$, respectively. Respiratory therapists at the non-teaching hospital had the best handwashing compliance $(52.6 \%)$. Nursing assistants at the teaching hospital had the worst compliance (11.5\%). Nursing assistant was the only health-care worker category with a significant difference between the two ICUs (odds ratio $=6.0 ; 95 \%$ confidence interval $=3.83-9.43 ; p<0.001$ )

Key Words: Compliance, handwashing, healthcare workers, intensive care.
\end{abstract}

A patient under hospital care is at risk of acquiring a nosocomial infection and, as is known since Semmelweis 150 years ago, there is a strong relationship between hand contamination and infection, with handwashing being the main measure of prevention [1]. Doebelling [2] demonstrated that improvement in hand hygiene practices by health care workers is significantly related to reduction in nosocomial infection rates.

Unfortunately, compliance with handwashing is still very low at most institutions [3-5]. The risk of irritating the hands, distance from washing facilities, and a lack of time, are the reasons usually presented to explain poor adherence [5-7].

Pittet et al. [8] observed that overall handwashing adherence was often below $50 \%$ in studies performed during the last 20 years. Recently, the introduction of alcohol-based hand gel has been effective in increasing hand hygiene compliance, especially in intensive care units $[9,10]$.

There have been few studies about handwashing in Latin America. Nogueras et al. [11] found a great difference between the number of colony-forming units (CFU) on healthcare workers hands, before and after physical examination of patients. They also found potential pathogens on the hands, such as Staphylococcus aureus [50\% methicillin resistant Staphylococcus aureus (MRSA)], E. coli, Pseudomonas aeruginosa and Enterococcus faecalis.

Brazil also has low compliance rates for handwashing practices; we evaluated such compliance in two intensive care units (ICUs) in São Paulo, one belonging to a universityaffiliated hospital and another in a non-teaching hospital. This is the first study evaluating handwashing compliance at two Brazilian hospitals.

Received on 10 December 2005; revised 17 February 2006.

Address for correspondence:Dr. Guilherme Furtado, 1226, Rua Dr. Diogo de Faria St. apt. 102, São Paulo, SP, CEP: 04037-004, Brazil. Fax: +55 11 5571-8935. Phone: +55 11 5908-0291.E-mail: ghfurtado@uol.com.br.

The Brazilian Journal of Infectious Diseases 2006;10(1):33-35. (C) 2006 by The Brazilian Journal of Infectious Diseases and Contexto Publishing. All rights reserved.

\section{Material and Methods}

The two hospitals were: the São Paulo Hospital, located in the city of São Paulo, which is a public institution, universityaffiliated, with 660 beds and seven ICUs, and the Diadema State Hospital, also public and located in Diadema, in the São Paulo metropolitan region, with 170 beds and three ICUs. Both hospitals had infection-control teams. There were seven infection control professionals (three physicians and four nurses with training in infection control) in the teaching hospital. The non-teaching hospital had an infection-control team with two infection control professionals (a physician and an infection-control nurse). No change was made in the teams during the study.

The study was performed in a 16-bed medical-surgical ICU in São Paulo Hospital and in an 11-bed medical-surgical ICU in Diadema State Hospital. The non-teaching ICU had a mean of 309 patient-days, 8.3 urinary tract infections/1,000 urinary catheter-days, 8.3 bloodstream infections/1,000 central-line days and 24.3 pneumonias/1,000 ventilator-days. The teaching ICU had a mean of 447 patient-days, 11.1 urinary tract infections/ 1,000 urinary-catheter-days, 14.8 bloodstream infections $/ 1,000$ central line-days and 10.4 pneumonias/1,000 ventilator-days.

The study was performed simultaneously in the two hospitals during a three-month period, from April 1 through June 30, 2003. An observer of the infection-control team observed handwashing opportunities for 30-minute periods, during the daytime shifts. The non-teaching hospital had three sinks in the ICU, while the teaching hospital had five. Chlorhexidine (2\%) was used as antiseptic soap in the two ICUs. Alcohol-based hand gel was not used in the two hospitals during the study period.

Each member of the ICU health-care staff was observed directly. The healthcare professionals working in the ICUs were not informed that the study was being performed, and performance feedback was not reported during the study. Variables studied were: professional category and relationship between the patient number and nursing team number. No training in handwashing was performed during the three months prior to the study. 
The following recommendations for handwashing were observed:

- Before and after direct contact with patients and devices;

- Before and after invasive procedures (including intravenous therapy);

- Before and after the handling of surgical wounds.

Compliance with handwashing was defined as washing the hands with water and an antiseptic solution (2\% chlorhexidine). Failure to remove gloves after contact with a patient or contact with the same patient's dirty and clean body sites was also considered non-compliance.

We used univariate analysis to examine the associations between a professional category of health-care worker and compliance. Proportions were compared by using Chi-square tests, with a $\mathrm{p}$ value of less than 0.05 being considered statistically significant. We used SPSS statistical software (version 10.0; SPSS, Inc., Chicago, IL).

\section{Results}

There were 495 opportunities for handwashing in the nonteaching hospital and 521 in the teaching hospital. The mean compliance rates were $42.6 \%$ and $22.2 \%$ in the non-teaching and in the teaching hospitals, respectively. Handwashing compliance was greatest in the group of respiratory therapists in the non-teaching (52.6\%) and teaching hospital (47\%) (Table 1). The lowest compliance was in the group of physicians $(24 \%)$ in the non-teaching hospital and in the nursing assistant group $(11.5 \%)$ in the teaching hospital. The patient/nursing ratio was 1.7 in the non-teaching hospital and 0.9 in the teaching hospital. In a comparison between the professional staff of the two hospitals, the only group with a significant difference was the nursing assistants $(\mathrm{p}<0.001)$.

During the study period, no epidemic outbreak was observed in the two facilities and no changes were made in the infection-control team.

\section{Discussion}

Our study showed a worrisome feature: a very low compliance with handwashing $(11.5 \%)$ in the nursingassistant group in the teaching hospital, which is a large university-affiliated institution. There was a significant difference when compared with the non-teaching hospital. In the other professional groups, though the differences were not significant, we found lower handwashing compliance of nurses and respiratory therapists and better compliance in the teaching hospital only in the physician group $(\mathrm{p}=0.92)$.

There were more opportunities for nursing assistants to wash their hands in both teaching $(66.2 \%)$ and non-teaching hospitals $(46.6 \%)$, while low compliance was found mainly at the teaching hospital (11.5\%), where there were more patients colonized or infected with multidrug-resistant bacteria, which is also a reason for concern. Gould et al. [12] found that a high demand for hand cleansing (reflecting high workloads) was associated with low compliance; but the patient-nursery ratio at the teaching hospital (0.7) was lower than in the nonteaching hospital (1.7), which would not justify the lower handwashing compliance if heavy workloads were the motive for non-compliance. Also, the patient-nurse ratio in the two ICUs did not seem to be unacceptable.

The mean ratio of the infection-control team/1,000 patientdays during the study period in the non-teaching and teaching hospitals were 0.43 and 0.48 , respectively, likewise not justifying the less time spent by the infection-control team in preventing infections in the teaching hospital ICU. Time spent with handwashing in hospitals averages 8 to 20 seconds, which is not enough to be fully effective 1,10 and, if 40 opportunities for hand hygiene appear per hour of care, the total time spent with handwashing becomes prohibitive; a solution is to use bedside hand antisepsis $[13,14]$.

Handwashing compliance by women is greatest, as demonstrated by Van de Mortel et al. [15] and by Sharir et al. [16] and, although this aspect was not evaluated during our study, the mean compliance of our study was respectively: respiratory therapists $(49.6 \%)$, nursing assistants $(30.1 \%)$, nurses $(27.2 \%)$ and physicians $(25.4 \%)$, with the first three groups of professionals being mainly females. The better handwashing compliance among respiratory therapists (49.6\%) has great importance because they are directly in contact with respiratory secretions in patients under mechanical ventilation, which are often colonized with multidrug-resistant pathogens. The better handwashing compliance in this group may reduce cross- transmission between patients of pathogens such as Pseudomonas aeruginosa and Acinetobacter baumanni, which often colonize the respiratory tract.

Rosenthal et al. [17], in a study performed in Argentina, demonstrated that handwashing practices and health-care worker $(\mathrm{HCW})$ education significantly improved $\mathrm{HCW}$ adherence to handwashing; however, after performance feedback was incorporated, handwashing compliance increased to a far greater degree. Our study did not evaluate steps to improve handwashing compliance, since we only wanted a base-line evaluation of handwashing compliance in the two medical-surgical ICUs.

Pittet et al. [18] observed a significant improvement in hand hygiene compliance after an educational program. There were also a decrease in nosocomial infection rates and MRSA transmission. Harbarth [19] also reported an increase in hand hygiene adherence in a pediatric hospital, after the introduction of alcohol-based hand gel and educational efforts.

The use of alcohol-based hand gel is progressively spreading in Brazilian hospitals, especially after the publication of the last CDC guideline for hand hygiene in health-care settings in 2002 [20]. Further studies are necessary to evaluate 
Table 1. Handwashing opportunities compliance in two intensive care units

\begin{tabular}{lcccr}
\hline Type of health-care worker & Non-teaching hospital & Teaching hospital & Odds-ratio & p \\
\hline Nursing Assistant & $144 / 328(43.9 \%)$ & $28 / 243(11.5 \%)$ & $6.01(3.83-9.43)$ & $<0.001$ \\
Nurse & $15 / 41(36.6 \%)$ & $33 / 135(24.4 \%)$ & $1.78(0.84-3.76)$ & 0.18 \\
Physician & $12 / 50(24 \%)$ & $16 / 60(26.7 \%)$ & $0.87(0.37-2.06)$ & 0.92 \\
Respiratory therapists & $40 / 76(52.6 \%)$ & $39 / 83(47 \%)$ & $1.25(0.67-2.34)$ & 0.58 \\
\hline
\end{tabular}

handwashing compliance after introduction of alcohol-based hand gel in our hospitals.

In summary, we found a low mean overall compliance with handwashing in two ICUs $(32.1 \%)$, with less compliance in the teaching-hospital ICU (22.2\%), and we also found a significant difference in compliance with handwashing in the nursing assistants of the two ICUs $(\mathrm{p}<0.001)$. We did not find a causal relation between workload and insufficient handwashing, which suggests that a lack of education may be an important factor, especially in the teaching hospital. Implementation of steps to improve handwashing compliance are needed, including HCW education, new handwashing practices (such as introduction of alcohol-based hand gel) and performance feedback.

\section{References}

1. Larson E.L. APIC Guideline for handwashing and hand antisepsis in health-care settings. Am J Infect Control 1995;23:251-69

2. Doebbeling B.N., Stanley G.L., Sheetz C.T., et al. Comparative efficacy of alternative hand-washing agents in reducing nosocomial infections in intensive care units. N England J Med 1992;327(2):88-93

3. Karabey S., Ay P., Derbentli S., et al. Handwashing frequencies in an intensive-care unit. J Hosp Infect 2002; 50: 36-41

4. Roberts L., Bolton P., Asman S. Compliance with handwashing practices: theory versus practice. Aust Health Rev 1998;21:238-44.

5. Voss A., Widmer A.F. No time for handwashing? Handwashing versus alcoholic rub: can we afford $100 \%$ compliance? Infect Control Hosp Epidemiol 1997;18:205-8.

6. Kaplan L.M., McGuckin M. Increasing handwashing compliance with more accessible sinks. Infect Control 1986;7:408-10.

7. McCormick R.D., Buchman T.L., Maki D.G. Double blind, randomized trial of scheduled use of a novel barrier cream and an oil-containing lotion for protecting the hands of healthcare workers. Am J Infect Control 2000;28:302-10.
8. Pittet D. Improving adherence to hand hygiene practice: A multidisciplinary approach. Emerg Infect Dis 2001;7(2):234-9.

9. Bischoff W.E., Reynolds T.M., Sessler C.N.,et al. Handwashing compliance by healthcare workers. The impact of introducing an accessible alcohol-based hand antiseptic. Arch Intern Med 2000; $160: 1017-21$.

10. Maury E., Alzieu M.,Baudel J.L., et al. Availability of na alcohol solution can improve hand disinfection compliance in an intensive care unit. Am J Resp Crit Care Med 2000;162:324-7.

11. Nogueras M., Marinsalta N., Roussell M., Notario R. Importance of hand germ contamination in health-care workers as possible carriers of nosocomial infections. Rev Inst Med Trop 2001;43(3):149-52.

12. Gould D. Nurse's hand-decontamination practice: results of a local study. J Hosp Infect 1994;28:15-30.

13. Rotter M.L. Handwashing and hand disinfection. In: Mayhall CG, ed. Hospital Epidemiology and Infection Control. Baltimore: Williams \& Wilkins; 1996:1052-68.

14. Pittet D., Mourouga P., Perneger T.V. Compliance with handwashing in a teaching hospital. Ann Intern Med 1999; 130:126-30.

15. Van de Mortel T., Bourke R., McLoughlin J., et al. Gender influences handwashing rates in the critical-care unit. Am J Infect Control 2001;29:395-9.

16. Sharir R., Teitler N., Lavi I., Raz R. High-level handwashing compliance in a community teaching hospital: a challenge that can be met! J Hosp Infect 2001;49:55-8.

17. Rosenthal V.D., McCormick R.D.,Guzman S.,et al. Effect of education and performance feedback on handwashing: the benefit of administrative support in Argentinean hospitals. Am J Infect Control 2003;51:85-92.

18. Pittet D., Hugonnet S., Harbarth S., et al. Effectiveness of a hospital-wide program to improve compliance with hand hygiene. Lancet 2000; 356:1307-12.

19. Harbarth S., Pittet D., Grady L., et al. Interventional study to evaluate the impact of an alcohol-based hand gel in improving hand hygiene compliance. Pediatr Infect Dis J 2002;21:48995 .

20. Guideline for hand hygiene in health-care settings. MMWR 2002;51(16). 